\title{
ANALISIS PREDIKSI TINGKAT KELULUSAN MAHASISWA UNIVERSITAS WIRALODRA INDRAMAYU MENGGUNAKAN METODE FUZZY TSUKAMOTO
}

\author{
Muhamad Dandi $^{1}$, Kinky Fernando ${ }^{2}$, Taufik Hidayat ${ }^{3}$ \\ ${ }^{1,2,3}$ Department of Computer Engineering, Universitas Wiralodra, Indonesia \\ ${ }^{1}$ muhamaddandi768@gmail.com, ${ }^{2}$ kinkifernando@gmail.com, ${ }^{3}$ thidayat.ft@unwir.ac.id
}

\begin{abstract}
ABSTRAK
Universitas Wiralodra merupakan Universitas swasta pertama di Indramayu, terletak di Kota Indramayu, Jawa Barat. Seiring dengan perjalanannya, Universitas Wiralodra terus berbenah untuk meningkatkan kapasitasnya, melalui peningkatan kualitas Sumber Daya Manusia (SDM) Dosen, Manajemen, kegiatan mahasiswa, penelitian dan publikasi, serta perbaikan sarana dan prasarana kampus. Kelulusan merupakan suatu hal yang dapat diharapkan oleh setiap mahasiswa, yang nantinya akan menjadi bekal seseorang mahasiswa dalam menempuh jenjang selanjutnya. Permasalahannya apakah mahasiswa Universitas Wiralodra bisa lulus dengan maksimal atau tidak. Dalam penelitian lebih memfokuskan bagaimana implementasi teori logika fuzzy dalam memprediksi tingkat kelulusan mahasiswa Universitas Wiralodra. Teori logika fuzzy ini digunakan karena mudah untuk dimengerti. Pada Penelitian ini menggunakan teori fuzzy tsukamoto dengan 2 variabel input yang terdiri dari jumlah penerimaan wisuda dan jumlah mahasiswa yang akan menhasilkan status jumlah mahasiswa yang lulus. Tujuan dari penelitian ini yaitu untuk memprediksi jumlah mahasiswa yang lulus dalam setiap tahunnya di Universitas Wiralodra Indramayu. Pada penelitian selanjutnya agar keputusan dalam menganalisis kondisi tingkat kelulusan mahasiswa agar digabungkan metode fuzzy tsukamoto dan markov chain agar masalah yang terjadi dalam memprediksi tingkat kelulusan mahasiswa dapat lebih akurat.
\end{abstract}

Kata Kunci : Teori logika fuzzy, Fuzzy tsukamoto, Prediksi kelulusan mahasiwa, Wisuda.

\begin{abstract}
Wiralodra University is the first private university in Indramayu, located in Indramayu City, West Java. Along with its journey, Wiralodra University continues to improve to increase its capacity, through improving the quality of Human Resources (HR) for lecturers, management, student activities, research and publications, as well as improvements to campus facilities and infrastructure. Graduation is something that can be expected by every student, which will later become a provision for a student to take the next level. The problem is whether Wiralodra University students can graduate optimally or not. This research focuses more on how to implement fuzzy logic theory in predicting the graduation rate of Wiralodra University students. This fuzzy logic theory is used because it is easy to understand. This study uses the Tsukamoto fuzzy theory with 2 input variables consisting of the number of graduation admissions and the number of students that will result in the status of the number of students who graduate. The purpose of this study is to predict the number of students who graduate each year at the University of Wiralodra Indramayu. In further research, the decision to analyze the condition of the student's graduation rate should be combined with the Tsukamoto fuzzy method and the Markov chain so that the problems that occur in predicting student graduation rates can be more accurate.
\end{abstract}

Keywords: Fuzzy logic theory, fuzzy Tsukamoto, Prediction of student graduation, Graduation. 


\section{PENDAHULUAN}

Dalam tiap institut tiap tahunnya tentu terdapat mahasiswa yang telah lulus serta begelar. Buat tiap tahunnya mahasiswa yang lulus bisa hadapi penyusutan ataupun hadapi kenaikan. Bila dilihat dari informasi partisipan yang mengikuti wisuda bisa dikatakan jika setiap tahunnya mahasiswa yang lulus tidak tentu, terkadang mengalami penyusutan ataupun terkadang mengalami kenaikan. Untuk memprediksi jumlah mahasiswa yang lulus digunakan suatu teori yaitu logika fuzzy, pada logika fuzzy ada sebagian tata cara yaitu metode tsukamoto, mamdani, serta sugeno [1], [2]. Dari ketiga metode tersebut ada perbandingan serta memiliki karakterstik yang berbeda. Namun pada penelitian ini lebih memfokuskan pada metode fuzzy tsukamoto. Logika fuzzy diperkenalkan awal kali oleh professor [3], [1]. Lutfi A. Zadeh, profesor. Lutfi seseorang periset dari Universitas California di Barkley dalam bidang ilmu computer pada tahun 1965. Dia berkomentar kalau logika benar ataupun salah tidak bisa mewakili pemikiran manusia, sehabis itu dikembangkanlah logika fuzzy yang sanggup mewakili pemikiran manusia [4]. Pada sesuatu teori himpunan fuzzy diketahui yang namanya derajat keanggotaan. Derajat keanggotaan ialah anggota yang ada di dalam sesuatu elemen himpunan fuzzy [5], [6]. Nilai keanggotaan tersebut terletak di dalam selang [0-1].

Bila dalam sesuatu himpunan fuzzy derajat keanggotaannya kurang dari 0 ataupun lebih dari 1, hingga nilai tersebut tidak tercantum dalam derajat keanggotaan himpunan fuzzy . Logika fuzzy merupakan salah satu pembuat soft compoting. Dasar dari logika fuzzy merupakan teori himpunan fuzzy. Derajat keanggotaan mempunyai peranan yang sangat berarti ialah bagaikan penentu keberadaan sesuatu elemen dalam sesuatu himpunan. Dalam teori fuzzy diketahui yang namanya teori fuzzy tata cara tsukamoto [7]. Metode tsukamoto merupakan tata cara yang mana buat tiap konsekuen pada ketentuan IF- THEN wajib di representasikan pada sesuatu himpunan fuzzy dengan fungsi dari keanggotaan yang monoton.

Pada metode tsukamoto tiap rule yang terdapat diterapkan dengan memakai himpunan fuzzy dengan guna keanggotaan yang konstan, teori fuzzy tsukamoto merupakan tata cara yang mempunyai toleransi pada informasi serta sangat fleksibel. Kelebihan metode tsukamoto merupakan bertabiat intuitif serta bisa membagikan asumsi bersumber pada data yang bertabiat kualitatif, tidak akurat, serta ambigu.

Metode tsukamoto setiap ketentuannya direpresentasikan memakai himpunan fuzzy, dengan fungsi keanggotaan yang bertabiat monoton. Tiap konsekuensi yang ada pada ketentuan yang berupa IF- THEN wajib direpresentasikan dengan sesuatu himpunan fuzzy dengan guna keanggotaan yang monoton. Beberapa penelitian menyatakan bahwa untuk menganalisa kelulusan mahasiswa bisa diprediksi dengan beberapa metode [8], [9]. Begitupun metode fuzzy tsukamoto berhasil digunakan untuk memprediksi beberapa kasus. Oleh karena itu penelitian ini menggunakan metode fuzzy tsukamoto untuk menganalisa dalam memprediksi tingkat kelulusan mahasiswa di Universitas Wiralodra Indramayu.

\section{METODE PENELITIAN}

Metode yang digunakan dalam penelitian ini adalah metode fuzzy tsukamoto [10], dimana metode tsukamoto dalam penelitian ini digunakan unutk memprediksi kelulusan mahasiswa Universitas Wiralodra Indramayu. Langkah-langkah penelitian penyusunan perhitungan sistematis menggunakan metode fuzzy tsukamoto untuk menganalisa prediksi tingkat kelulusan mahasiswa Universitas Wiralodra melalui beberapa tahap diantaranya adalah sebagai berikut :

\section{A. Fuzzy Logic}

Logika fuzzy yang dikembangkan dari logika primitif namun hanya mengenal keadaan "ya" atau "tidak". Dengan logika fuzzy ini dapat mengenal peubah lingusitik seperti "Banyak", "Sedikit", “ Naik", "Turun", "Bertambah", "Berkurang" dan lain sebagainya. Dengan ini, sistem akan lebih adaptif karena menggunakan aplikasi logika fuzzy . Untuk membangun sebuah sistem dengan fuzzy logic dapat dibedakan beberapa jenis, antara lain : metode tsukumoto, metode mamdani dan metode sugeno. Dalam menganalisis tinkat 
kelulusan pada penelitian ini menggunakan fuzzy logic dengan metode tsukamoto [11].

\section{B. Tsukamoto Method}

Metode Tsukamoto merupaka setiap konsekuen pada aturan berbentuk IF-THEN harus dipresentasikan dengan suatu himpunan fuzzy, dengan fungsi keanggotaan yang monoton. Sebagai hasilnya, output hasil inferensi dari tiap-tiap aturan diberikan dengan berdasarkan predikat [12], [13]. Hasil akhir diperoleh dengan menggunakan rata-rata terbobot. Misalkan ada 2 variabel input, yaitu $x$ dan y serta satu variabel output $z$. Variabel $\mathrm{x}$ terbagi atas dua himpunan yaitu A1 dan A2, sedangkan variabel y terbagi atas himpunan B1 dan B2. Variabel $\mathrm{z}$ juga terbagi atas dua himpunan yaitu $\mathrm{C} 1$ dan $\mathrm{C} 2$. Tentu saja himpunan $\mathrm{C} 1$ dan $\mathrm{C} 2$ harus merupakan himpunan yang bersifat monoton [14], [15].

Untuk analisis prediksi tingkat kelulusan mahasiswa ini menggunakan metode fuzzy tsukamoto [16]. Berikut adalah gambaran dari variabel pada kelulusan mahasiswa yaitu jumlah penerimaan peserta wisuda dan jumlah mahasiswa yang dioverload tsukamoto sehingga menghasilkan status jumlah mahasiswa yang lulus.

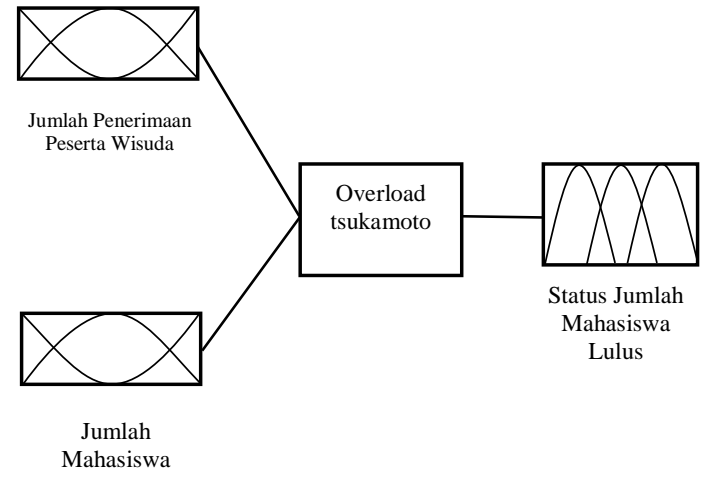

Gambar 1. Proses Fuzzy Tsukamoto Kelulusan Mahasiswa [17]

\section{Aturan Logika Kelulusan Mahasiswa}

Untuk Menentukan tingkat kelulusan mahasiswa tentunya harus dibuat aturan logika yang akan digunakan sebagai acuan dalam pengolahan data [18], [19]. Aturan logika yang digunakan ini dibuat sesuai dengan himpunan yang digunakan pada variabel jumlah penerimaan peserta wisuda dan jumlah mahasisawa sehingga dapat ditentukan suatu kondisi atau status jumlah yang lulus [20]. Berikut adalah aturan logika :

[R1] IF jumlah mahasiswa banyak dan jumlah penerimaan peserta wisuda naik THEN jumlah mahasiswa yang lulus bertambah.

[R2] IF jumlah mahasiswa banyak dan jumlah penerimaan peserta wisuda turun THEN jumlah mahasiswa yang lulus berkurang.

[R3] IF jumlah mahasiswa sedikit dan jumlah penerimaan peserta wisuda naik THEN jumlah mahasiswa yang lulus bertambah.

[R4] IF jumlah mahasiswa sedikit dan jumlah penerimaan peserta wisuda turun THEN jumlah mahasiswa yang lulus berkurang.

Tabel 1. Aturan Logika Kelulusan Mahasiswa

\begin{tabular}{|c|c|c|c|}
\hline \multirow{2}{*}{ Aturan } & \multicolumn{3}{|c|}{ Variabel Kelulusan } \\
\cline { 2 - 4 } & $\begin{array}{c}\text { Jumlah } \\
\text { Penerimaan }\end{array}$ & $\begin{array}{c}\text { Jumlah } \\
\text { Mahasiswa }\end{array}$ & $\begin{array}{c}\text { Status jumlah } \\
\text { yang lulus }\end{array}$ \\
\hline R1 & Banyak & Naik & Bertambah \\
\hline R2 & Banyak & Turun & Berkurang \\
\hline R3 & Sedikit & Naik & Bertambah \\
\hline R4 & Sedikit & Turun & Berkurang \\
\hline
\end{tabular}

\section{Data Source Kelulusan Mahasiswa}

Pada data source kelulusan mahasiswa yaitu atribut yang berisikan variabel-variabel kelulusan, informasi atribut yang berisikan informasi dari setiap variabel dari atribut, dan type data yang membedakan jenis data yang diinputkan [2], [21].

Tabel 2. Data Set Kelulusan Mahasiswa

\begin{tabular}{|c|c|c|}
\hline Atribut & Informasi Atribut & $\begin{array}{c}\text { Type } \\
\text { Data }\end{array}$ \\
\hline Waktu & $\begin{array}{c}\text { Waktu Data } \\
\text { Diperoleh }\end{array}$ & $\begin{array}{c}\text { Date and } \\
\text { Time }\end{array}$ \\
\hline $\begin{array}{c}\text { Jumlah } \\
\text { Penerimaan } \\
\text { Peserta } \\
\text { Wisuda }\end{array}$ & Naik, Turun & Numerik \\
\hline $\begin{array}{c}\text { Jumlah } \\
\text { Mahasiswa }\end{array}$ & Banyak, Sedikit & Numerik \\
\hline $\begin{array}{c}\text { Jumlah } \\
\text { Yang Lulus }\end{array}$ & $\begin{array}{c}\text { Bertambah, } \\
\text { Berkurang }\end{array}$ & Logical \\
\hline
\end{tabular}




\section{HASIL DAN PEMBAHASAN}

Dalam pengumpulan data yang digunakan dalam penelitian ini melalui studi kepustakaan. Dimana, pengumpulan datanya dilakukan dengan mengambil bahan dari dokumentasi, literatur, jurnal, dan web Universitas Wiralodra yang berhubungan dengan mahasiswa yang mengikuti wisuda. Sedangkan outputnya adalah dengan melihat jumlah mahasiswa yang lulus di Universitas Wiralodra. Data mahasiswa yang diperoleh dapat dilihat pada tabel berikut :

Tabel 3. Jumlah Data Mahasiswa

\begin{tabular}{|l|c|}
\hline \multicolumn{1}{|c|}{ Variabel } & $\begin{array}{c}\text { Jumlah Data } \\
\text { Diketahui }\end{array}$ \\
\hline $\begin{array}{l}\text { Jumlah Penerimaan } \\
\text { Peserta Wisuda }\end{array}$ & 300 \\
\hline Jumlah Mahasiswa & 1500 \\
\hline Jumlah Yang Lulus & Hasil Analisis \\
\hline
\end{tabular}

Untuk mengetahui jumlah data dari variabel jumlah mahasiswa yang akan lulus maka tentunya dari jumlah data yang diketahui yaitu jumlah data dari variabel jumlah penerimaan peserta wisuda dan jumlah mahasiswa akan dianalisis data tersebut, maka dibuat lah pengelompokan data sebagai berikut:

Tabel 4. Pengelompokan Data

\begin{tabular}{|c|c|c|}
\hline Variabel & Himpunan & $\begin{array}{c}\text { Nilai } \\
\text { Fuzzy }\end{array}$ \\
\hline $\begin{array}{c}\text { Jumlah } \\
\text { Penerimaan } \\
\begin{array}{c}\text { Peserta } \\
\text { Wisuda }\end{array}\end{array}$ & Naik & $100-400$ \\
\cline { 2 - 2 } & Turun & \\
\hline $\begin{array}{c}\text { Jumlah } \\
\text { Mahasiswa }\end{array}$ & Banyak & $1000-3000$ \\
\cline { 2 - 2 } & Sedikit & \\
\hline $\begin{array}{c}\text { Jumlah Yang } \\
\text { Lulus }\end{array}$ & Bertambah & $500-3000$ \\
\cline { 2 - 2 } & Berkurang & \\
\hline
\end{tabular}

Penyelesaian dari data-data tersebut yaitu dengan menggunakan metode tsukamoto. Penyelesaiannya dengan cara seperti berikut :

\section{A. Memodelkan variabel fuzzy \\ 1. Variabel penerimaan peserta wisuda}

Variabel penerimaan peserta wisuda terdiri dari 2 himpunan yaitu naik dan turun. Untuk fungsi keanggotaan penerimaan peserta wisuda direpresentasikan sebagai berikut:

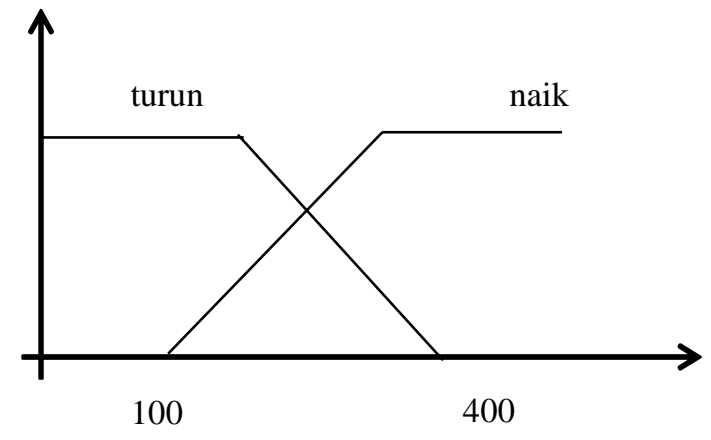

Gambar 2. Grafik Representasi kurva linier naik dan turun variabel $\mathrm{x}$

Fungsi keanggotaan dari himpunan naik dan turun dari variabel jumlah penerimaan peserta wisuda adalah:

$$
\begin{aligned}
& \mu \text { naik (x) : }\left\{\begin{array}{c}
x \leq 100 \\
0, x \geq 400
\end{array}\right. \\
& \mu \text { turun (x) : }\left\{\begin{array}{l}
0, \mathrm{x} \leq 100 \\
\frac{400-x}{300} 100 \leq x \leq 400 \\
1, \mathrm{x} \geq 400
\end{array}\right.
\end{aligned}
$$

Nilai keanggotaan himpunan naik dan turun dari variabel penerimaan peserta wisuda dapat diperoleh dengan cara sebagai berikut :

$\mu$ pener turun $(300): \frac{400-300}{300}$

$=\frac{100}{300}$

$=0,34$

$\mu$ pener naik (300) $: \frac{300-100}{300}$

$=\frac{200}{300}$

$=0,66$ 
2. Fungsi keanggotaan variabel jumlah mahasiswa

Variabel jumlah mahasiswa terdiri dari 2 himpunan yaitu banyak dan sedikit. Grafik untuk fungsi keanggotaan jumlah mahasiswa sebagai berikut:

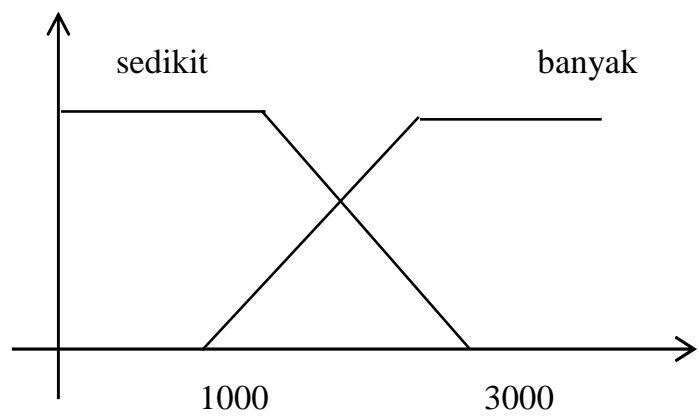

Gambar 3. Grafik Representasi kurva linier naik dan turun variabel y

Fungsi keanggotaan himpunan banyak dan sedikit dari variabel jumlah mahasiswa adalah :

$\mu$ sedikit $(\mathrm{y}):\left\{\begin{array}{l}0, \mathrm{y} \leq 100 \\ \frac{3000-y}{2000} 1000 \leq y \leq 3000 \\ 1, \mathrm{y} \geq 3000\end{array}\right.$

$\mu$ banyak $(\mathrm{y}):\left\{\begin{array}{l}1, \mathrm{y} \leq 1000 \\ \frac{y-1000}{2000} 1000 \leq x \leq 3000 \\ 0, \mathrm{y} \geq 3000\end{array}\right.$

Untuk nilai keanggotaan himpunan banyak dan sedikit dari variabel jumlah peserta dapat diperoleh dengan cara :

$\mu$ pener banyak (1500) : $\frac{3000-1500}{2000}$

$=\frac{1500}{2000}$

$=0,75$

$\mu$ pener sedikit (1500) $: \frac{1500-1000}{2000}$

$=\frac{500}{2000}$

$=0,66$
Variabel jumlah mahasiswa yang lulus terdiri dari 2 himpunan yaitu bertambah dan berkurang. untuk fungsi keanggotaannya direpresentasikan sebagai berikut.

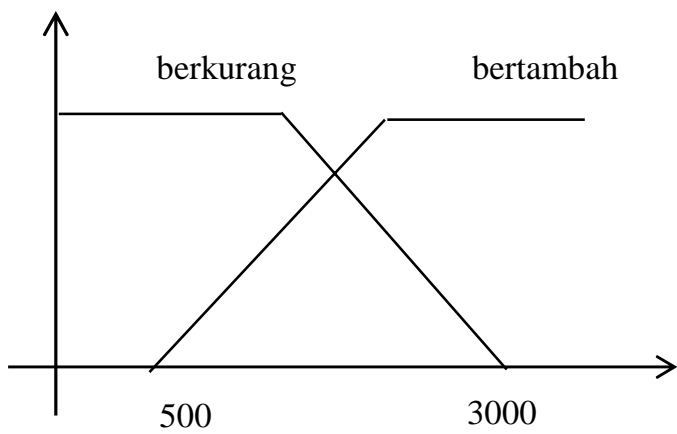

Gambar 4. Grafik Representasi kurva linier naik dan turun variabel z

Fungsi keanggotaan himpunan bertambah dan berkurang dari variabel jumlah mahasiswa yang lulus adalah :

$$
\begin{aligned}
& \mu \text { berkurang }(\mathrm{y}):\left\{\begin{array}{l}
0, \mathrm{z} \leq 500 \\
\frac{z-500}{2500} 500 \leq z \leq 3000 \frac{x-100}{300} 100 \leq x \leq 400 \\
1, \mathrm{z} \geq 3000
\end{array}\right. \\
& \mu \text { banyak (y) : }\left\{\begin{array}{l}
1, \mathrm{z} \leq 5001, \\
\frac{z-500}{2500} 500 \leq z \leq 3000 \frac{x-100}{300} 100 \leq x \leq 40 \\
0, \mathrm{z} \geq 3000
\end{array}\right.
\end{aligned}
$$

Untuk mencari nilai keanggotaan himpunan bertambah dan berkurang dari variabel jumlah mahasiswa yang lulus, maka harus dicari nilai z nya terlebih dahulu. Dimana untuk mencari nilai $\mathrm{z}$ pada setiap aturan maka digunakan fungsi MIN pada aplikasi fungsi. Digunakanlah yang namanya interferensi.

B. Aturan Inferensi

R1. IF jumlah mahasiswa banyak dan jumlah penerimaan peserta wisuda naik THEN jumlah mahasiswa yang lulus bertambah

$\alpha-$ predika $=\mu$ jumlah mahasiswa banyak n jumlah penurunan peserta wisuda naik

3. Fungsi keanggotaan variabel jumlah mahasiswa yang lulus $=\mu \min (\mu$ jumlah mahasiswa banyak $[1500], \mu$ penurunan wisuda naik [300] ) 


$$
\begin{aligned}
& =\min (0,75 ; 0,66) \\
& =0,66
\end{aligned}
$$

Himpunan jumlah mahasiswa bertambah adalah:

$$
\begin{array}{ll}
\frac{\mathrm{z}-\mathbf{5 0 0}}{\mathbf{2 5 0 0}} & =\mathbf{0 , 6 6} \\
\mathrm{z}-500 & =1650 \\
\mathrm{z}_{1} & =1150
\end{array}
$$

R2. IF jumlah mahasiswa banyak dan jumlah penerimaan peserta wisuda turun THEN jumlah mahasiswa yang lulus berkurang

$$
\begin{aligned}
& \text { wisuda turun }[300]) \\
= & \min (0,25 ; 0,34) \\
= & 0,25
\end{aligned}
$$

Himpunanjumlah mahasiswa bertambah adalah:

$$
\begin{aligned}
\frac{3000-z}{2500} & =0,25 \\
3000-\mathrm{z} & =625 \\
\mathrm{z}_{4} & =2375
\end{aligned}
$$

Setelah mencari nilai $\mathrm{z}$ pada masingmasing aturan inferensi, maka selanjutnya menentukan nilai output crisp.

$$
\begin{aligned}
\alpha-\text { predika }= & \mu \text { jumlah mahasiswa banyak } \\
& \cap \text { jumlah penurunan peserta } \\
& \text { wisuda turun } \\
= & \mu \min (\mu \text { jumlah mahasiswa } \\
& \text { banyak }[1500], \mu \text { penurunan } \\
& \text { wisuda turun }[300]) \\
= & \min (0,75 ; 0,34) \\
= & \mathbf{0 , 3 4}
\end{aligned}
$$

Himpunanjumlah mahasiswa berkurang adalah :

$$
\begin{array}{ll}
\frac{\mathbf{3 0 0}-\boldsymbol{z}}{\mathbf{2 5 0 0}} & =\mathbf{0 , 3 4} \\
3000-\mathrm{z} & =850 \\
\mathrm{z}_{2} & =2150
\end{array}
$$

R3. IF jumlah mahasiswa sedikit dan jumlah penerimaan peserta wisuda naik THEN jumlah mahasiswa yang lulus bertambah

$$
\begin{aligned}
\alpha-\text { predika }= & \mu \text { jumlah mahasiswa sedikit } \\
& \begin{array}{l}
\text { jumlah penurunan peserta } \\
\text { wisuda naik }
\end{array} \\
= & \mu \min (\mu \text { jumlah mahasiswa } \\
& \text { sedikit }[1500], \mu \text { penurunan } \\
& \text { wisuda naik }[300]) \\
= & \min (0,25 ; 0,66) \\
= & \mathbf{0 , 2 5}
\end{aligned}
$$

Himpunanjumlah mahasiswa bertambah adalah:

$$
\begin{array}{ll}
\frac{\boldsymbol{z}-\mathbf{5 0 0}}{\mathbf{2 5 0 0}} & =\mathbf{0 , 2 5} \\
\mathrm{z}-500 & =625 \\
\mathrm{z}_{3} & =125
\end{array}
$$

R4. IF jumlah mahasiswa sedikit dan jumlah penerimaan peserta wisuda turun THEN jumlah mahasiswa yang lulus berkurang

$\alpha-$ predika $=\mu$ jumlah mahasiswa sedikit $n$ jumlah penurunan peserta wisuda turun

$=\mu \min (\mu$ jumlah mahasiswa sedikit $[1500], \mu$ penurunan
C. Menentukan Nilai Crisp.

Untuk menentukan output crisp maka digunakan perhitungan sebagai berikut :

$$
Z=\frac{(\alpha 1 . z 1)+(\alpha 2 . z 2)+(\alpha 3 . z 3)+(\alpha 4 . z 4)}{\alpha 1+\alpha 2+\alpha 3+\alpha 4}
$$

$z=\frac{0,66 \cdot 1150+0,34 \cdot 2150+0,25 \cdot 125+0,25 \cdot 2375}{0,66+0,34+0,25+0,25}$

$Z=\frac{759+731+31_{s} 25+593_{s} 75}{1_{v} 5}$

$Z=\frac{2115}{1,5}$

$Z=1410$

D. Uji Data Tingkat Kelulusan Mahasiswa

Jadi kesimpulannya untuk jumlah mahasiswa yang lulus setiap tahunnya sekitar 1.410 mahasiswa. Dimana jumlah tersebut bisa dikatakan jumlah yang cukup banyak. Pada tahap pertama yaitu memodelkan variabel fuzzy utuk mempernudah dalam perhitungan himpunan fuzzy.

Pada tahap ini terdapat tiga variabel dimana pada setiap variabel tersebut direpresentasikan dengan bentuk grafik sesuai dengan aturan metode tsukamoto. Kemudian dihitung nilai keanggotaan dari setiap himpunan fuzzy tersebut dan nilai tersebut terletak di dalam selang $[0,1]$.

Untuk tahap kedua yaitu tentang aturan inferensi, dimana aturan tersebut merupakan sebuah bentuk kerja perhitungan yang berdasar pada konsep teori himpunan fuzzy. Sesuai dengan definisi tersebut jika dilihat dari 
perhitungan inferensi diatas, yaitu sebuah perhitungan yang berdasar pada himpunan fuzzy yang sudah diperoleh sebelumnya.

Pada tahap yang terakhir yaitu menentukan output crisp untuk mengetahui nilai kebenaran dari operasi logika yang digunakan. Output crisp merupakan sebuah keputusan yang diperoleh dari hasil pengolahan logika. Dimana output crisp tersebut digunakan untuk mendapatkan keputusan tingkat kebenaran dari operasi logika yang digunakan. Sesuai dengan pernyataan tersebut diketahui bahwa jumlah penerimaan peserta wisuda yaitu sebanyak 300 dan jumlah tersebut termasuk pada kategori naik dan jumlah mahasiswa sebanyak 1500 dan masuk pada kategori banyak. Dari perhitungan output crisp diperoleh jumlah mahasiswa yang lulus yaitu sebanyak 1.410. sesuai dengan aturan inferensi bahwa ketika jumlah penerimaan peserta naik dan jumlah mahasiswa banyak maka tingkat kelulusan akan bertambah.

Tabel 4. Hasil Data Pengolahan Tingkat Kelulusan Mahasiswa

\begin{tabular}{|c|c|c|}
\hline Keterangan & Jumlah & Presentase \\
\hline Mahasiswa Lulus & 1410 & $94 \%$ \\
\hline $\begin{array}{c}\text { Mahasiswa Tidak } \\
\text { Lulus }\end{array}$ & 90 & $6 \%$ \\
\hline
\end{tabular}

Dari tabel diatas dapat dibuat grafik seperti gambar dibawah ini :

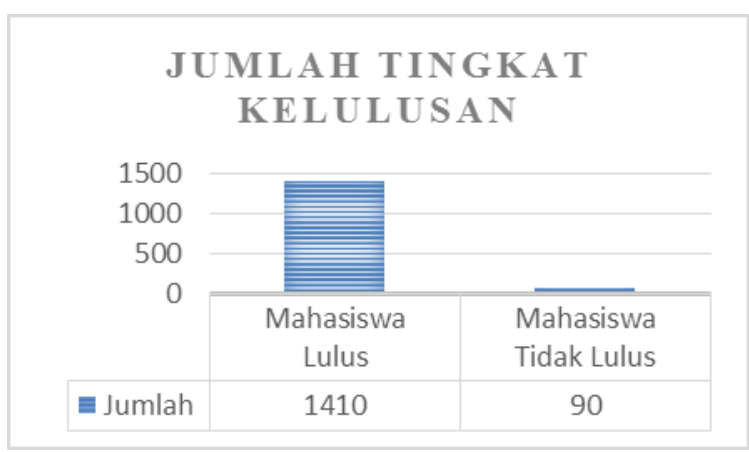

Gambar 5. Grafik Hasil Pengujian Berdasarkan Jumlah Tingkat Kelulusan

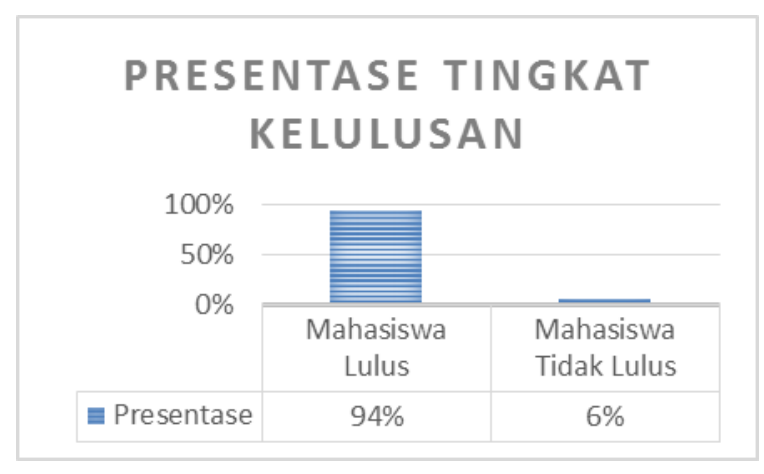

Gambar 6. Grafik Hasil Pengujian Berdasarkan Presentase Tingkat Kelulusan

\section{KESIMPULAN}

Dari hasil pengujian ini telah menunjukan korelasi dari setiap variabelnya yang diolah dengan menggunakan teori fuzzy tsukamoto sehingga dapat membantu dalam memprediksi jumlah mahasiswa yang lulus dan tidak lulus, meskipun sistem ini tidak menentukan secara pasti jumlah mahasiswa yang lulus, karena disesuaikan dengan jumlah mahasiswa dan jumlah penerimaan wisuda. Penelitian ini dapat diselesaikan dengan beberapa tahap yaitu Memodelkan variabel fuzzy, Aturan inferensi atau aturan logika, dan Menentukan output crisp. Hasil yang diperoleh mahasiswa yang lulus sekitar 1.410. dimana jumlah tersebut jika dipresetasekan sebesar 94\% dari jumlah mahasiswa sehingga bisa dikatakan sudah cukup banyak tingkat kelulusan dari jumlah mahasiswa.

\section{UCAPAN TERIMAKASIH}

Penulis mengucapkan terimakasih kepada Department of Computer Engineering dan Universitas Wiralodra yang selalu mendukung dan membantu riset kami.

\section{DAFTAR PUSTAKA}

[1] F. Camastra et al., "A fuzzy decision system for genetically modified plant environmental risk assessment using Mamdani inference," Expert Systems with Applications, vol. 42, no. 3, pp. 1710-1716, 2015, doi: 10.1016/j.eswa.2014.09.041.

[2] J. O. Oladipo, A. S. Akinwumiju, O. S. Aboyeji, and A. A. Adelodun, "Comparison between fuzzy logic and 
water quality index methods: A case of water quality assessment in Ikare community, Southwestern Nigeria," Environmental Challenges, vol. 3, no. January, p. 100038, 2021, doi: 10.1016/j.envc.2021.100038.

[3] F. Topaloğlu and H. Pehlivan, "Comparison of Mamdani type and Sugeno type fuzzy inference systems in wind power plant installations," 6th International Symposium on Digital Forensic and Security, ISDFS 2018 Proceeding, vol. 2018-Janua, pp. 1-4, 2018, doi: 10.1109/ISDFS.2018.8355384.

[4] B. R. Raghunath and B. Annappa, "Dynamic Resource Allocation Using Fuzzy Prediction System," in 2018 3rd International Conference for Convergence in Technology (I2CT), Apr. 2018, pp. 1-6, doi: 10.1109/I2CT.2018.8529674.

[5] J. Singla, "Comparative study of Mamdani-type and Sugeno-type fuzzy inference systems for diagnosis of diabetes," Conference Proceeding 2015 International Conference on Advances in Computer Engineering and Applications, ICACEA 2015, pp. 517522, 2015, doi: 10.1109/ICACEA.2015.7164799.

[6] A. Son and E.-N. Huh, "Study on a migration scheme by fuzzy-logic-based learning and decision approach for QoS in cloud computing," in 2017 Ninth International Conference on Ubiquitous and Future Networks (ICUFN), Jul. 2017, pp. 507-512, doi: 10.1109/ICUFN.2017.7993836.

[7] G. Casalino, G. Castellano, and C. Mencar, "Incremental and Adaptive Fuzzy Clustering for Virtual Learning Environments Data Analysis," in 2019 23rd International Conference Information Visualisation (IV), Jul. 2019, vol. 2019-July, no. Iv, pp. 382387, doi: 10.1109/IV.2019.00071.

[8] H. Thakkar, V. Shah, H. Yagnik, and M. Shah, "Comparative anatomization of data mining and fuzzy logic techniques used in diabetes prognosis," Clinical eHealth, vol. 4, pp. 12-23, 2021, doi: 10.1016/j.ceh.2020.11.001.

[9] F. B. Goularte, S. M. Nassar, R. Fileto, and $\mathrm{H}$. Saggion, "A text summarization method based on fuzzy rules and applicable to automated assessment," Expert Systems with Applications, vol. 115 , pp. 264-275, 2019, doi: 10.1016/j.eswa.2018.07.047.

[10] K. Mittal, A. Jain, K. S. Vaisla, O. Castillo, and J. Kacprzyk, "A comprehensive review on type 2 fuzzy logic applications: Past, present and future," Engineering Applications of Artificial Intelligence, vol. 95, no. December 2018, p. 103916, Oct. 2020, doi: 10.1016/j.engappai.2020.103916.

[11] Weihua Huang, Zhong Ma, Xinfa Dai, Yi Gao, Mingdi $\mathrm{Xu}$, and Huafeng $\mathrm{Wu}$, "Load balancing algorithm for virtual cluster using fuzzy clustering," in 2016 2nd IEEE International Conference on Computer and Communications (ICCC), Oct. 2016, pp. 313-320, doi: 10.1109/CompComm.2016.7924715.

[12] M. Dandi and T. Hidayat, "Analisis Prediksi Problem Virtual Machine Server Menggunakan Metode Fuzzy Logic," vol. 3, no. 1, pp. 1-6, 2020.

[13] T. Hidayat and M. Alaydrus, "Performance Analysis and Mitigation of Virtual Machine Server by using Naive Bayes Classification," in 2019 Fourth International Conference on Informatics and Computing (ICIC), Oct. 2019, pp. 1-5, doi: 10.1109/ICIC47613.2019.8985932.

[14] B. M. P. Moura, G. B. Schneider, A. C. Yamin, M. L. Pilla, and R. H. S. Reiser, "Allocating Virtual Machines exploring Type-2 Fuzzy Logic and Admissible Orders," in 2019 IEEE International Conference on Fuzzy Systems (FUZZIEEE), Jun. 2019, vol. 2019-June, pp. $1-6, \quad$ doi: 10.1109/FUZZIEEE.2019.8858827.

[15] M. H. Eghbal Ahmadi, S. J. Royaee, S. Tayyebi, and R. Bozorgmehry Boozarjomehry, "A new insight into implementing Mamdani fuzzy inference system for dynamic process modeling: Application on flash separator fuzzy dynamic modeling," Engineering 
Applications of Artificial Intelligence, vol. 90, no. March 2019, p. 103485, 2020 , doi:

10.1016/j.engappai.2020.103485.

[16] K. Belarbi, F. Titel, W. Bourebia, and K. Benmahammed, "Design of Mamdani fuzzy logic controllers with rule base minimisation using genetic algorithm," Engineering Applications of Artificial Intelligence, vol. 18, no. 7, pp. 875-880, 2005 , doi: 10.1016/j.engappai.2005.03.003.

[17] M. F. Adak, "Software defect detection by using data mining based fuzzy logic," in 2018 Sixth International Conference on Digital Information, Networking, and Wireless Communications (DINWC), Apr. 2018, pp. 65-69, doi: 10.1109/DINWC.2018.8356997.

[18] S. Suthar, R. Verma, S. Deep, and K. Kumar, "Optimization of conditions ( $\mathrm{pH}$ and temperature) for Lemna gibba production using fuzzy model coupled with Mamdani's method," Ecological Engineering, vol. 83, pp. 452-455, 2015 , doi: 10.1016/j.ecoleng.2015.07.006.

[19] N. Mijović, M. Kalić, and J. Kuljanin, "Tuning the fuzzy logic system by two meta-heuristics: case study of airline market share on long-haul routes," Transportation Research Procedia, vol. 52, no. 2020, pp. 453-460, 2021, doi: 10.1016/j.trpro.2021.01.053.

[20] F. Ramezani and M. Naderpour, "A fuzzy virtual machine workload prediction method for cloud environments," in 2017 IEEE International Conference on Fuzzy Systems (FUZZ-IEEE), Jul. 2017, pp. 16, doi: 10.1109/FUZZIEEE.2017.8015450.
[21] N. Ghamry and L. S. Nasrat, "Fuzzy logic approach for the prediction of the lifetime of epoxy insulators," in 2015 12th International Conference on Fuzzy Systems and Knowledge Discovery (FSKD), Aug. 2015, pp. 426-432, doi: 10.1109/FSKD.2015.7381980. 